\title{
Probabilistic Approach for Assessing Rock Mass Quality in the Tunnel
}

\section{Krishna Kanta Panthi}

Abstract: Rock mass is a heterogeneous media and the quality of the rock mass may change within a very short distance. As a result, on many occasions considerable discrepancies (variations) have been found between the predicted and actual rock mass conditions along the tunnel alignment, resulting in significant cost and time overruns. Finding innovative solutions for quantifying the quality of rock mass and assessing the risk of discrepancies are, therefore, key issues for cost effective and optimum tunneling solutions in the Himalayan region.

In this paper, a probabilistic approach of uncertainty analysis has been proposed to evaluate the quality of rock mass based on the Q-system of rock mass classification. Mapped rock mass quality data from the Modi headrace tunnel from Nepal have been used as a case study. The degree of correlation between the simulated results achieved by a probabilistic assessment using @Risk and values actually measured in the tunnel have been discussed. It is concluded that the probabilistic approach can be used as a tool in predicting rock mass quality and assessing risk in tunneling projects.

Key words: Probabilistic approach, rock mass quality, tunnel, Nepal

\section{Introduction}

W $\begin{array}{ll}\text { any tunnels } & \text { built } \\ \text { around } & \text { the }\end{array}$ experience considerable variation between the predicted and actual rock mass conditions. Particularly, it is the case in most of the tunneling projects built in the Himalayan region. The variations in the predicted and actual rock mass quality generally leads to a considerable increase in the rock support requirement and also to a certain extent the need for increased quantities of tunneling machinery compared to what is being anticipated during planning. Minimizing the quality variations in advance (at project planning),

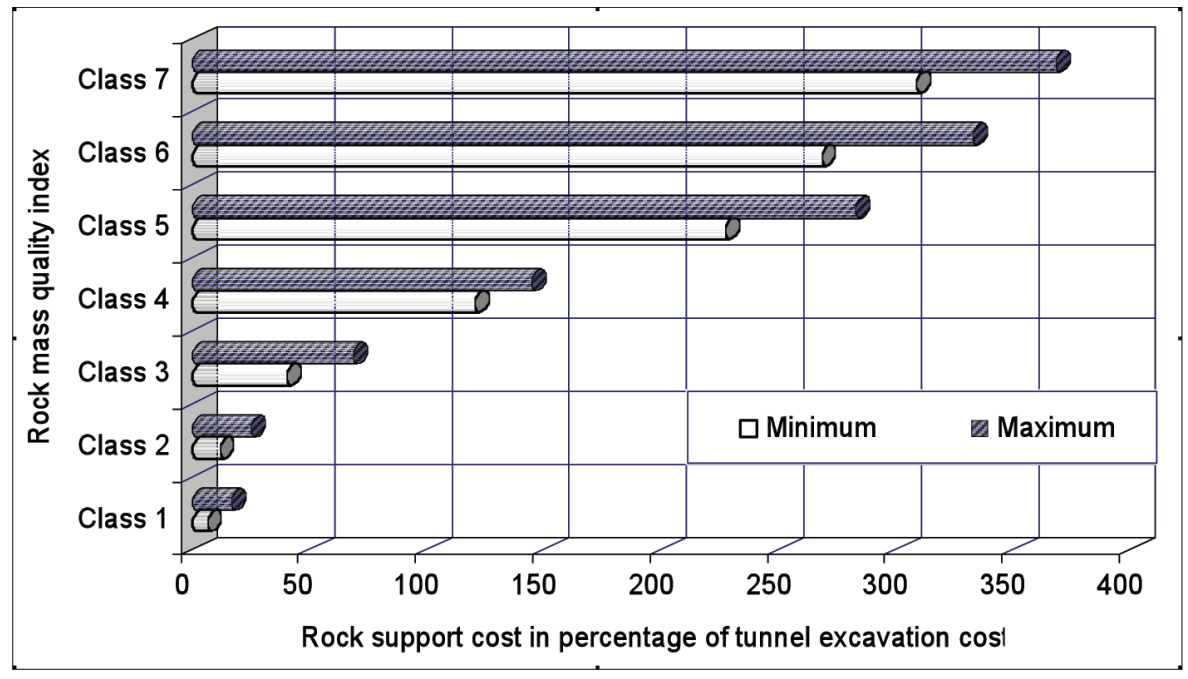

Figure 1. Approximate Rock Support Cost for Different Rock Mass Classes (Minimum and Maximum for Small and Large Section Tunnels, respectively). Meaning of Rock Mass Quality: Class 1 - Extremely Good; Class 2 - Very Good; Class 3 - Fair to Good; Class 4 - Poor; Class 5 - Very Poor; Class 6 - Extremely Poor and Class 7 - Exceptionally Poor (Panthi 2006). controlling tunnel support costs

and construction time are, therefore, very essential to make tunneling projects attractive and feasible.

Given the heterogeneous nature of the rock mass, it is almost impossible to eliminate all uncertainties related to rock mass quality deviations. Still, it is important to control variations within acceptable limits because unexpectedly large discrepancies between the predicted and actual rock mass conditions in the tunnel have a direct link to the tunnel project cost and construction time. Moreover, such discrepancies give room for claims from the contractor since he/she will need additional resources to deal with the difficult conditions that he/she did not anticipate during bidding. It will be a big setback to the client, which may create an environment for unnecessary contractual disputes, claims and counter claims. As a consequence, the completion of the project within the projected construction schedule may not be possible, and additional economic loss due to revenue lost by delayed start of the project operation and by increased interest during construction will also be the case.

Figure 1 illustrates the cost implication that will be caused by changes in rock mass quality conditions. The figure defines the relative tunnel support cost for different rock mass quality classes in relation to the tunnel excavation costs.

As Figure 1 indicates, as soon as the rock mass quality decreases (higher class), there is a dramatic increase in the tunnel rock support cost. For example, if the predicted rock mass quality class belonged to "Fair to good" (class 3 , then the cost of the tunnel rock support would be approximately 50 percent of the tunnel excavation cost. In the same locality, if actually encountered rock mass quality are mapped with "Poor" (class 4) category (which is very frequent in the Himalayan tunneling), the tunnel 
rock support cost will be more than 125 percent of the excavation cost. This discrepancy (variation) in the rock mass class will lead to the increase of tunnel rock support cost by more than twofold. If the actually encountered rock mass quality is mapped with "Very poor" (class 5) category (which can also be the case in many Himalayan tunneling works), the tunnel rock support cost will increase dramatically (almost four times the originally predicted costs). How to control this risk of variation is a real challenge to the tunnel project management team.

Therefore, finding innovative solutions in predicting rock mass quality is important. The aim of this paper is directed towards this problem. The paper attempts to look at the potentiality of using the probabilistic approach of uncertainty analyses to assess the quality of the rock mass. An uncertainty model is proposed and the model is used to correlate the rock mass quality predicted during planning with the quality of the rock mass actually mapped during tunnel excavation. Discussions are also made on whether such an approach could be used in real life. The rock mass quality index data from the Modi Khola headrace tunnel are used as a case study in this endeavor.

\section{Proposed Methodology for the Assessment}

The methodology proposed for a probabilistic approach of uncertainty analysis in predicting and quantifying the probable distribution of rock mass quality given in Figure 2. As Figure 3 indicates, while carrying out a probabilistic assessment, it is important to characterize the most representative probability distribution functions (pdf) for the input parameters related to the uncertainty in concern (Panthi 2006). This is because the representative of each input parameters are the only possible way to reliably and quantitatively predict the probability distribution of the output of an uncertainty.

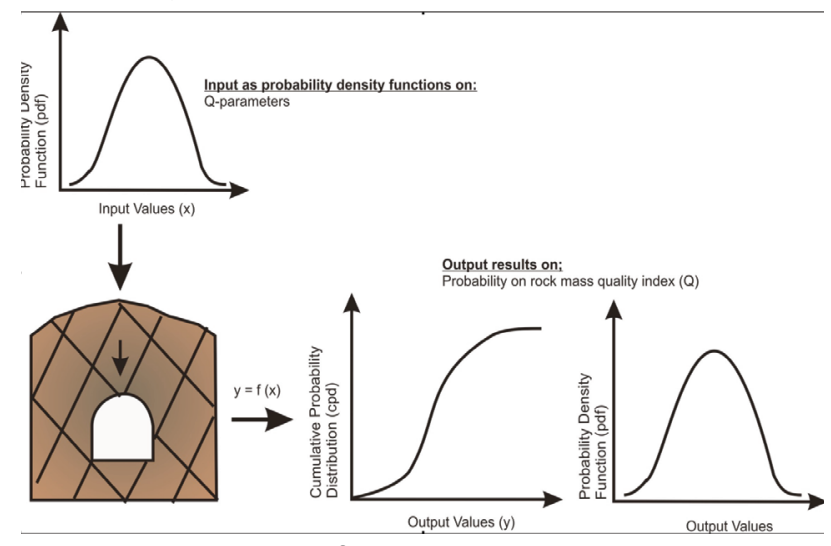

Figure 2. Principle Model for Uncertainty Analysis.

Even though, any type of uncertainty analysis may be carried out based on the approach given in Figure 3, this paper mainly focuses only on the uncertainty analysis for the assessment of the rock mass quality index (Q). The software program @Risk, an advanced statistical risk analysis software introduced by Palisade Corporation in 1996 and updated in 2002 (version 4.5), has been used as a computing tool to realize the model proposed in Figure 3 .

\section{Brief About the Case Tunnel Project}

The Modi Khola hydroelectric project generates 91 GWh of electrical energy annually. The project has a medium head of approximately 67 meters and a design discharge $27.5 \mathrm{~m}^{3} / \mathrm{s}$ (NEA 2000). The project consists

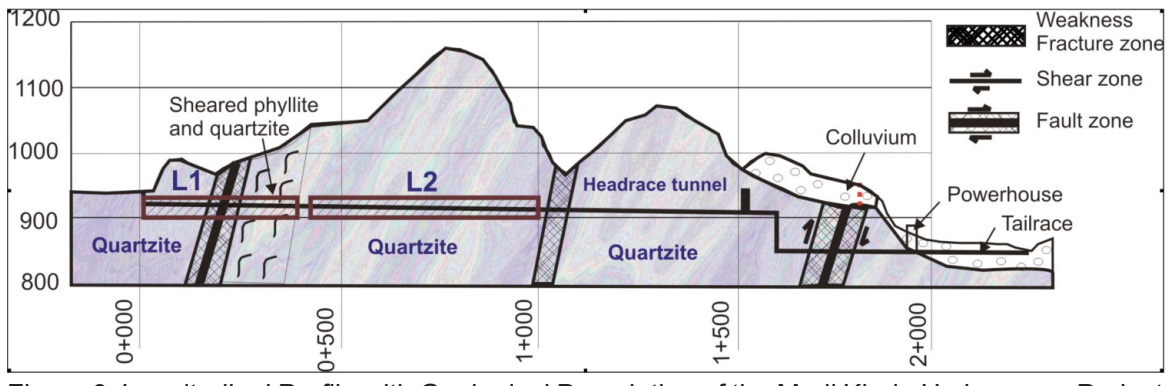

file with Geological Description of the Modi Khola Hydropower Project. L1 and L2 are Headrace Tunnel Segments Selected for the Analysis. of total underground waterway length of approximately 2 kilometers (Figure 3). The tunnel system includes a 1,503 meter long headrace tunnel with a cross section of approximately 15 square meters, a 50 meter deep vertical pressure shaft and a 430 meter long pressure tunnel.

Geologically, the project area lies in the Precambrian sequence of the lesser Himalayan meta-sedimentary rock formations. The bedrock along the underground waterways of this project is mainly dominated by fractured and abrasive quartzite (Himal Hydro 2001). The first 500 meter upstream section of the headrace tunnel passes through a weakness zone consisting of highly fractured quartzite and highly sheared and deformed phyllite in intercalation (Figure 3). With the well exposed rock along the Modi River, the rock mass conditions along this tunnel alignment were not difficult to predict. As a result, the deviation between the predicted and actual rock mass condition was not that significant as experienced in other tunneling projects in the Himalayan region.

The rock mass conditions observed during excavation along the headrace tunnel and vertical shaft were found to be of good quality ranging from greenish to white quartzite. However, exceptions were found in the tunnel section passing through weakness and fracture zones where rock mass quality was of very poor to extremely poor quality class (Himal Hydro 2001).

The tunnel mapping records indicate that there exist three sets of joints and occasional random joints along the tunnel alignment. The discontinuities present in the rock mass were found to be slight to moderately weathered with some degree of alteration. Most of the discontinuities were smooth undulating to smooth 
planner. The discontinuities were filled with a thin layer of silty clay fragments. In addition, thin bands of highly sheared green to dark gray mica schist were found intercalated within massive quartzite at some locations (Himal Hydro 2001).

\section{Probabilistic Assessment of Rock Mass Quality}

Natural outcrops, excavated road cut slopes, borehole cores, geophysical investigation results and excavated tunnel faces are the most common sources of information that are used for classifying the rock mass quality index. It is generally accepted that quantification of input parameters in most of the classification systems are very subjective and mostly dependent on the personal judgement of the user. The subjectivity and the extent of variations among the observers in quantifying input parameters of some of these classification systems have been discussed by Nilsen et al (2003).

In this paper, two tunnel segments (segments L1 and L2) from the Modi headrace tunnels (Figure 3) are used as examples for the probabilistic assessment. The Q-system of rock mass classification, which was used to quantify the quality of rock mass in this tunnel, is used as a basis for the analysis. The rock quality index (Q) is a function of six variable input parameters and is described by the following equation as suggested by Barton et al (1974):

$$
Q=f(x)=\frac{R Q D}{J_{n}} \times \frac{J_{r}}{J_{a}} \times \frac{J_{W}}{S R F}
$$

In the equation: RQD is the rock quality designation that represents the degree of jointing and its rating varies from 10 to $100 ; \mathrm{J}_{\mathrm{n}}$ is the joint set number that varies from

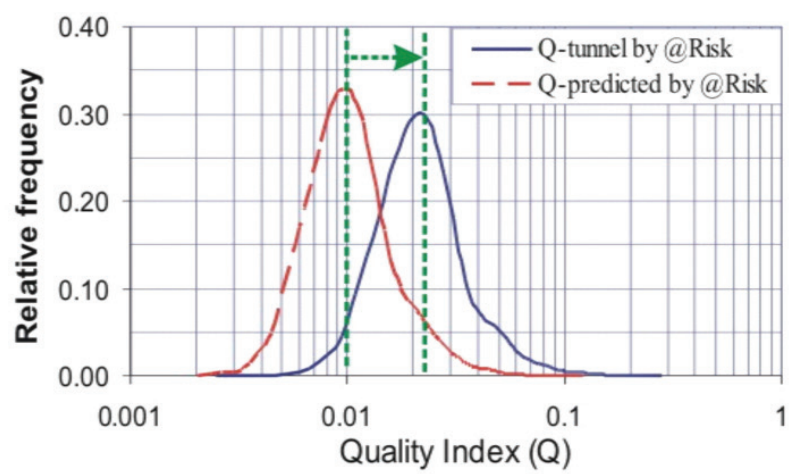

20 to $0.5 ; \mathrm{J}_{\mathrm{r}}$ is the joint roughness number that varies from 0.5 to $4 ; \mathrm{J}$ is the joint alteration number that varies from 20 to $0.75 ; \mathrm{J}_{\mathrm{w}}$ is the joint water reduction factor that varies from 0.05 to 1 , and SRF is the stress reduction factor that varies from 400 to 1.

It should be emphasized here that higher rating numbers of the denominator in Equation $1\left(\mathrm{~J}_{\mathrm{n}}, \mathrm{J}\right.$ and SRF) contribute to the reduction of the Q-value. Therefore, while assigning probability density functions (pdf) representating the denominators $\mathrm{J}_{\mathrm{n}}, \mathrm{J}_{\mathrm{a}}$ and SRF, it should be kept in mind that the higher values give smaller values with respect to rock quality index (Q).

In terms of probabilistic assessment, the rock mass quality index (Q) should be considered as an uncertainty (variable) that is dependable on these six variable input parameters, and all six variables given in Equation 1 are considered to be independent with respect to each other. The main principle of the probabilistic assessment based on the Q-value is thus to characterize the uncertainties that exist while estimating these six variable input parameters. Characterization of these uncertain input variables is done by assigning probability density functions (pdf) to each of them. Logical judgement, mapped input variables in the tunnel during excavation and the best fit tool are used to define the probability density function (pdf) for each input variable.

\section{Segment L1 with Very Weak Rock Mass (Chainage 0-325)}

This section of the headrace tunnel has a relatively low overburden of less than 100 meters (see Figure 3). During planning, this section was considered to be a highly fractured zone with a potential of moderate groundwater

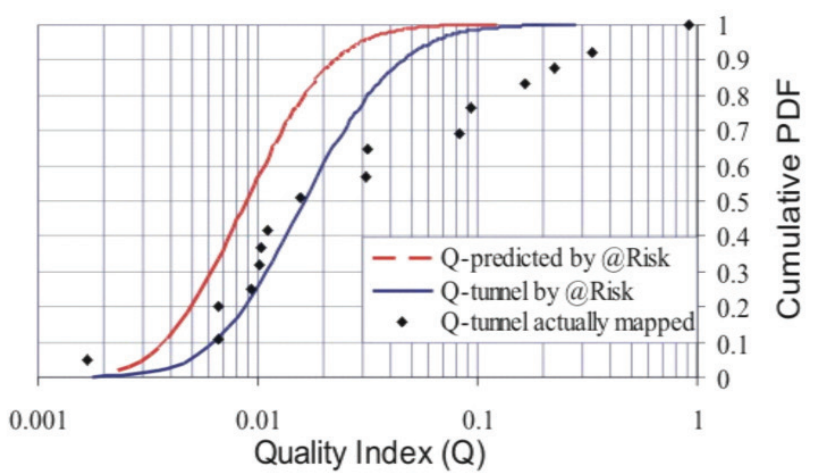

Figure 4. Distribution of Quality Index Q between Chainage 0-325m of the Modi Khola Headrace Tunnel.
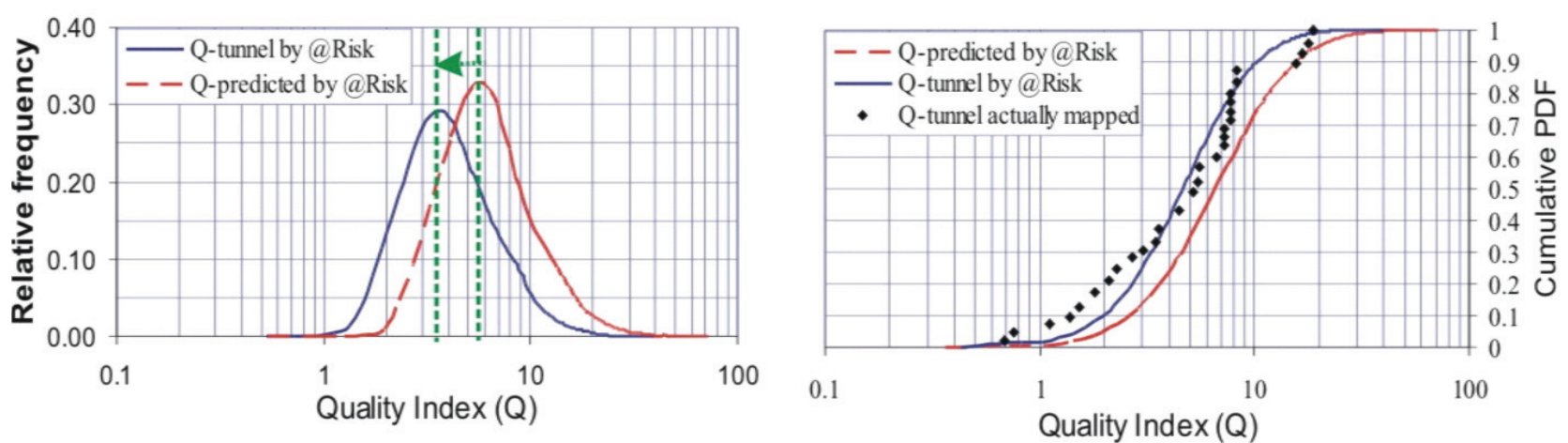

Figure 5. Distribution of Q between Chainage 325-1025m (Segment L2) of the Modi Khola Headrace Tunnel. 
inflow. In reality, the rock mass was found to be highly weathered and extremely weak, representing a weakness zone. In the tunnel, the rock mass in the upstream section of approximately 225 meters was found mainly to consist of highly fractured and extremely weathered quartzite with frequent intercalations of bands of extremely weak, highly sheared phyllitic schist. After this, the rock mass was dominated by a shear zone consisting of highly sheared phyllitic schist until chainage $325 \mathrm{~m}$.

Defining Probability Density Functions (pdf): The predicted and actual ranges of input variables for the Q-values with their minimum, maximum, mean and most likely or median values are given in Table 1 . In addition, the assumed probability density functions (pdf) of each input variable and mapped value for the simulation of @ Risk model are also given in the table.

Achieved simulation results: The @Risk uncertainty analysis model was run after defining and assigning the probability density functions (pdf) for each input variable of the quality index (Q) given in Table 1. The outcomes of the pseudo-randomly distributed rock mass quality index (Q) based on simulation by @Risk are shown in Figure 4 .

The figure shows the relative frequency (probability density) and cumulative distributions of the Q-values representing the iteration results based on @ Risk for both predicted and actual rock mass conditions. The cumulative diagram also includes the distribution of actually mapped Q-values recorded during excavation for the first 325 meter long tunnel section (L1).

Figure 4 shows that the probability distributions for the actual and predicted ranges of the rock mass conditions are very close to each other. The rock mass actually encountered was of slightly better quality than was anticipated during the prediction. The main reason for this was the thickness of the sheared phyllitic schist, which was found to be shorter than estimated during planning.

The cumulative probability distribution as calculated from the actual tunnel data by @Risk and the distribution

\begin{tabular}{|c|c|c|c|c|c|c|}
\hline \multirow{2}{*}{$\begin{array}{c}\text { Descriptions of } \\
\text { Q-value } \\
\text { Parameters }\end{array}$} & \multicolumn{5}{|c|}{ Rating Ranges Of Q-Value Parameters } & \multirow{2}{*}{$\begin{array}{l}\text { Assumed Probability Density Function } \\
\text { (pdf) }\end{array}$} \\
\hline & $\begin{array}{l}\text { Min. } \\
\left(x_{\min }\right)\end{array}$ & $\begin{array}{l}\text { Max. } \\
\left(x_{\max }\right)\end{array}$ & $\begin{array}{c}\text { Mean / } \\
\text { Most Likely }\end{array}$ & $\begin{array}{l}\text { St. dev. } \\
\text { (s) }\end{array}$ & $\begin{array}{l}\text { @ Risk } \\
\text { Value }\end{array}$ & \\
\hline \multicolumn{7}{|l|}{ A. Predicted } \\
\hline RQD & 10 & 40 & 25 & 15 & 26.28 & Lognormal, Truncate $(10 ; 100)$ \\
\hline$J_{n}$ & 20 & 9 & 15 & & 14.67 & Triangular, Truncate $(1 ; 20)$ \\
\hline $\mathbf{J}_{\mathrm{r}}$ & 0.5 & 1.5 & 1 & 0.5 & 1.07 & Lognormal, Truncate $(0.5 ; 4)$ \\
\hline $\mathbf{J}_{\mathbf{a}}$ & 15 & 8 & 15 & 5 & 13.47 & Lognormal, Truncate $(0.75 ; 20)$ \\
\hline $\mathbf{J}_{\mathbf{w}}$ & 0.5 & 0.66 & 0.5 & & 0.55 & Triangular, Truncate $(0.05 ; 1)$ \\
\hline SRF & 10 & 5 & 7.5 & & 7.50 & Triangular, Truncate $(1 ; 10)$ \\
\hline Q-value & 0.001 & 0.110 & 0.007 & & 0.010 & \\
\hline \multicolumn{7}{|l|}{ B. Actual } \\
\hline RQD & 10 & 55 & 25 & 15 & 26.28 & \multirow{6}{*}{ Same as above } \\
\hline$J_{n}$ & 20 & 12 & 15 & & 15.67 & \\
\hline $\mathbf{J}_{\mathbf{r}}$ & 0.5 & 2 & 1 & 0.5 & 1.07 & \\
\hline $\mathbf{J}_{\mathrm{a}}$ & 20 & 6 & 12 & 5 & 11.09 & \\
\hline $\mathbf{J}_{\mathrm{w}}$ & 0.5 & 1 & 0.66 & & 0.72 & \\
\hline SRF & 10 & 2.5 & 6.3 & & 6.25 & \\
\hline Q-value & 0.001 & 0.611 & 0.015 & & 0.019 & \\
\hline
\end{tabular}

Table 1. Predicted and Actual Ranges of Input Parameters for Q-value with Assigned Probability Density Functions (pdf) for Chainage $0-325 \mathrm{~m}$ of the Modi Khola Headrace Tunnel.

of actually mapped values of the quality indexes $\mathrm{Q}$ in the tunnel are in close agreement for the Q-values with lower ranges (less than 0.02), see Figure 4 right. For the higher Q-values (above 0.02), the actually mapped Q-values do not show a good correlation with the cumulative distribution of Q-values calculated by @Risk.

\section{Segment L2 with Fair to Good Quality Rock Mass (Chainage 325-1025m)}

This section of the Modi Khola headrace tunnel (Figure 3) has a moderate overburden (between 75 and 250 meters). The rock mass mainly consists of very was found to be slightly more altered and weathered than anticipated during the prediction.

The cumulative distribution as calculated from the actual data by @Risk and the distribution of actually mapped values of the quality index $\mathrm{Q}$ are also found to be in close agreement (see Figure 5 right). As seen in the left figure, there is a good overlap in the frequency distributions for the predicted and actually mapped Q-values. This indicates that the assigned probability density functions of the input variables in Table 2 are representative and may represent the real ground conditions. 
hard, abrasive, fresh to slightly weathered and jointed quartzite. The discontinuity surfaces in the tunnel were observed to be altered and filled with silt and clay, but the overall quality of the rock mass observed in the tunnel was found to be of fair to good quality, as predicted during planning.

Defining probability density functions (pdf): The predicted and actual ranges of the input variables for the Q-value with their minimum, maximum, mean and most likely values are given in Table 2 . In addition, the assumed probability density functions (pdf) of each input variable and mapped value for simulation by @ Risk are also given in the table.

Achieved simulation results: The @Risk uncertainty analysis model was run after defining and assigning probability density functions (pdf) for each input variable of the $\mathrm{Q}$-value given in Table 2. The outcomes of the pseudo-randomly distributed rock mass quality index (Q) based on simulation by @ Risk are shown in Figure 5 .

Figure 5 shows relative frequency (probability density) and cumulative distributions of the Q-values representing the iteration results based on @Risk for the predicted and actual rock mass conditions. The cumulative diagram also includes the distribution of Q-values recorded during excavation, in this case for a 700 meter long tunnel section.

As shown in Figure 5, the probability distributions based on @Risk for actual and predicted ranges of the rock mass conditions are very close. The actual rock mass

\section{Discussions and Conclusions}

As described, these two segments of the headrace tunnel represent two different scenarios with respect to the predicted and actual rock mass conditions, and are, therefore, valuable for the discussion concerning the sensitivity of the assessment. The rock mass quality rating is influenced by the degree of jointing as well asthe degree of weathering and alteration.

In the tunnel segment L1 (Chainage $0-325 \mathrm{~m}$ ), very poor quality rock mass was predicted, and the rock mass actually found in the tunnel was also mapped in the same category with some positive deviation, which means improved rock mass quality than predicted. The simulated results of the probability distribution achieved by @Risk are not very different from the predicted and actually mapped rock mass quality for the lower values; i.e. for Q-values less than 0.02. On the other hand, the distribution achieved by @ Risk gave slightly smaller values than actually mapped. This indicates some discrepancies but not to a high degree than expected. Similarly, in the tunnel segment L2 (Chainage 325 - $1025 \mathrm{~m}$ ) where fair to good quality rock mass was predicted, the actually found rock mass quality was also in the same rock class category. The simulated results of the probability distributions for the quality index $Q$ based on @ Risk are very similar to that actually mapped in the tunnel thereby granting validity to the applicability of the proposed probability assessment model.

Hence, it can be concluded here that the probabilistic approach for evaluating rock mass quality can be used in real life and is a useful methodology. More importantly, such analysis may prove to be a valuable tool to make

\begin{tabular}{|c|c|c|c|c|c|c|}
\hline \multirow{2}{*}{$\begin{array}{c}\text { Descriptions of } \\
\text { Q-value } \\
\text { Parameters }\end{array}$} & \multicolumn{5}{|c|}{ Rating Ranges Of Q-Value Parameters } & \multirow{2}{*}{$\begin{array}{l}\text { Assumed Probability Density Function } \\
\text { (pdf) }\end{array}$} \\
\hline & $\begin{array}{l}\text { Min. } \\
\left(\mathbf{x}_{\min }\right)\end{array}$ & $\begin{array}{l}\text { Max. } \\
\left(x_{\max }\right)\end{array}$ & $\begin{array}{c}\text { Mean / } \\
\text { Most Likely }\end{array}$ & $\begin{array}{l}\text { St. dev. } \\
\text { (s) }\end{array}$ & $\begin{array}{l}\text { @ Risk } \\
\text { Value }\end{array}$ & \\
\hline \multicolumn{7}{|l|}{ A. Predicted } \\
\hline RQD & 60 & 90 & 75 & 15 & 73.45 & Normal, Truncate $(10 ; 100)$ \\
\hline $\mathbf{J}_{\mathrm{n}}$ & 9 & 4 & 6 & & 6.33 & Triangular, Truncate $(1 ; 20)$ \\
\hline $\mathbf{J}_{\mathrm{r}}$ & 1 & 3 & 2 & 1 & 2.08 & Normal, Truncate $(0.5 ; 4)$ \\
\hline $\mathbf{J}_{\mathbf{a}}$ & 3 & 1 & 2 & 1 & 2.20 & Normal, Truncate $(0.75 ; 20)$ \\
\hline $\mathbf{J}_{\mathbf{w}}$ & 0.66 & 1 & 1 & & 0.89 & Triangular, Truncate $(0.05 ; 1)$ \\
\hline SRF & 2.5 & 1 & 1 & & 1.50 & Triangular, Truncate $(1 ; 10)$ \\
\hline Q-value & 0.58 & 67.50 & 12.50 & & 6.48 & \\
\hline \multicolumn{7}{|l|}{ B. Actual } \\
\hline RQD & 50 & 85 & 65 & 10 & 65.00 & \multirow{6}{*}{ Same as above } \\
\hline$J_{n}$ & 12 & 9 & 9 & & 10.00 & \\
\hline $\mathbf{J}_{\mathrm{r}}$ & 1 & 3 & 2 & 1 & 2.08 & \\
\hline $\mathbf{J}_{\mathbf{a}}$ & 4 & 1 & 2 & 1 & 2.20 & \\
\hline $\mathbf{J}_{\mathrm{w}}$ & 0.66 & 1 & 1 & & 0.89 & \\
\hline SRF & 1.5 & 1 & 1 & & 1.17 & \\
\hline Q-value & 0.45 & 28.33 & 7.22 & & 4.67 & \\
\hline
\end{tabular}

Table 2. Predicted and Actual Ranges of Input Parameters for the Q-value with Assigned Probability Density Functions (pdf) for Chainage 325-1025m (Segment L2) of the Modi Khola Headrace Tunnel. 
risk assessment in tunneling projects, which certainly helps to reduce large discrepancies (variations) between the predicted and actually encountered rock mass quality along the tunnel alignment.

Krishna Kanta Panthi, PhD, is an Associate Professor in Geological Engineering in the Department of Geology and Mineral Resources Engineering, Norwegian University and Science and Technology (NTNU), Trondheim, Norway. He has completed his Dr. Ing. degree on the 'Analysis of Engineering Uncertainties Related to Tunneling in the Himalayan Rock Mass Conditions' in 2006 from NTNU. He completed his M.Sc. in Hydropower Development in 1998 and M.Sc. in Civil Engineering in 1992. He is the author of many scientific papers related to tunneling, rock slope engineering and hydropower. He has over 15 years of experience in the design, construction and planning of tunneling and hydropower projects in the Himalaya (Nepal and India).

Corresponding Address: krishna.panthi@ntnu.no

References

Barton N., R. Line and J. Linde, 1974, Engineering Classification of Rock Masses for the Design of Tunnel Support. Rock Mechanics, vol. 6, pp. 189-236.
Barton N., 2002, Some Q Value Correlation to Assist in Site Characterization and Tunnel Design. International journal of rock mechanics and mining sciences, vol. 39, pp. 185-216.

Himal Hydro, 2001, Construction Report. Modi Khola Hydroelectric Project, Nepal.

Nilsen B., Shrestha G. L., Panthi K. K., Holmøy K. H. and Olsen V. 2003. Classification Comparisons: RMR vs Q vs RMi. Tunnels and Tunnelling International. May 2003.

Nepal Electricity Authority (NEA), 2000, Completion Report for Headrace Tunnel and Surge Shaft. Modi Khola Hydroelectric Project, Nepal.

Panthi K. K., 2006, Analysis of Engineering Geological Uncertainties Related to Tunneling in Himalayan Rock Mass Conditions. Based on chapters 4, 5, 6 and 7. Norwegian University of Science and Technology. Doctoral theses at NTNU 2006:41. ISBN 82-4717826-5. http://www.diva-portal.org/ntnu/abstract. xsql?dbid $=711$.

Panthi K. K. and B. Nilsen, 2007, Predicted Versus Actual Rock Mass Conditions: A Review of Four Tunnel Projects in Nepal Himalaya. Tunneling and Underground Space Technology, vol 22, no. 2, pp 173-184.

\section{CALENDAR OF EVENTS - ENVIRONMENT}

7-10 August, 2012: Biodiversity Asia 2012. Location: Bangalore (Bengaluru), India. More info: http:// www.scbasia2012.org

11-12 August, 2012: International Conference on Environment, Agriculture and Food Sciences (ICEAFS'2012). Location: Phuket, Thailand. More info: http://psrcentre.org/listing. php?subcid $=106 \&$ mode $=$ detail

25-26 October, 2012: Ecological balance: man and environment. Location: Saint Petersburg, Russian Federation. More info: http://en.lengu. $\mathrm{ru} /$ research/international-conferences/ecologicalbalance-man-and-environment

3-4 November, 2012: National Conference on Environment and Biodiversity of India. Location: New Delhi, India. More info: http://www. ebiconference.com/

5-6 November, 2012: 1st International Conference on Urban Sustainability and Resilience. Location: London, UK. More info: http://www.usarconference-2012.org/
16-17 November, 2012: 17th International Forestry and Environment Symposium 2012. Location: Nugegoda, Sri Lanka. More info: http://fesympo. sjp.ac.lk/

22-24 November, 2012: 5 th International Congress of Environmental Research. Location: Kuala Lumpur, Malaysia. More info: http://www.icer12. jerad.org

24-25 November, 2012: 3rd International Conference on Biology, Environment and Chemistry (ICBEC 2012). Location: Bangkok, Thailand. More info: http://www.icbec.org/

22-23 December, 2012: 2nd International Conference on Environment Science and Biotechnology-ICESB 2012. Location: Kuala Lumpur, Malaysia. More info: http://www.icesb. org/

24-27 February, 2013: International Conference on Natural Resources Management in a Changing World. Location: Abu-Dhabi, United Arab Emirates. More info: http://www.fos.uaeu.ac.ae/ conference/nrm/ 